Jurnal Kimia Sains dan Aplikasi 23 (4) (2020):109-116
ISSN: 1410-8917
Jurnal Kimia
Aplikasi
Journal homepage: http://ejournal.undip.ac.id/index.php/ksa

\title{
Improving the Performance of Zinc Oxide Photocatalysts for Phenol Degradation through Addition of Lanthanum Species
}

\author{
Wynona Agatha Nimpoeno ${ }^{a}$, Hendrik Oktendy Lintang ${ }^{a, b}$, Leny Yuliati ${ }^{a, b, *}$ \\ ${ }^{\text {a }}$ Department of Chemistry, Faculty of Science and Technology, Universitas Ma Chung, Malang 65151, East Java, Indonesia \\ ${ }^{\mathrm{b}}$ Ma Chung Research Center for Photosynthetic Pigments (MRCPP), Universitas Ma Chung, Malang 65151, East Java, Indonesia \\ *Corresponding author: leny.yuliati@machung.ac.id \\ https://doi.org/10.14710/jksa.23.4.109-116
}

\section{Article Info}

Article history:

Received: $8^{\text {th }}$ December 2019 Revised: $28^{\text {th }}$ January 2020

Accepted: $1^{\text {st }}$ February 2020

Online: $30^{\text {th }}$ April 2020

Keywords:

lanthanum; phenol

degradation;

photocatalysis; zinc oxide

\begin{abstract}
One green approach to degrade organic pollutants, such as phenol, is through the photocatalytic reaction. Despite having large band gap energy, which is enough for phenol degradation, zinc oxide ( $\mathrm{ZnO}$ ) has low photocatalytic efficiency. In this study, ZnO was modified by lanthanum (La) species, and the improved photocatalytic activity was confirmed for degradation of phenol under visible and ultraviolet (UV) light irradiation. The $\mathrm{ZnO}$ and its modified photocatalysts were prepared by the hydrothermal method in the absence and presence of La species (0.01-2 wt \%). X-ray diffraction (XRD) patterns showed that the addition of La did not disturb the structure of $\mathrm{ZnO}$, but slightly decreased the crystallite size. While the La addition up to $1 \mathrm{wt} \%$ did not affect the optical properties of the $\mathrm{ZnO}$, the addition of $2 \mathrm{wt} \%$ La slightly redshifted the absorption band edge of the ZnO. The Fourier-transform infrared (FT-IR) spectra showed La oxide formation observed at 515-540 $\mathrm{cm}^{-1}$ after $2 \mathrm{wt} \%$ La addition. Fluorescence emission spectra revealed that synthesized $\mathrm{ZnO}$ has oxygen vacancies at $558 \mathrm{~nm}$, and the presence of $1 \mathrm{wt} \%$ La did not significantly affect the emission intensity. The photocatalytic activity of $\mathrm{ZnO}$ was influenced by the La addition, where the best performance was obtained on the $\mathrm{ZnO}$ with $1 \mathrm{wt} \% \mathrm{La}$. This study demonstrated that the optimum amount of La species could increase the performance of the $\mathrm{ZnO}$.
\end{abstract}

\section{Introduction}

Phenol is an organic pollutant widely used in various industries such as paint, pesticide, polymer synthesis, and petroleum. As phenol is highly soluble in water and has toxicity in low concentrations [1], it is crucial to treat phenol in wastewater. Various methods, including physical and chemical treatments, have been developed to treat phenol. Some physical methods are distillation [2], adsorption [3], and extraction [4], while some chemical methods are Fenton [5], ozonation [6], and photochemical processes [7]. However, these methods still have low efficiency [8], and thus, alternative methods are still required. Recently, many types of research have been extensively carried out to develop phenol removal methods through heterogeneous photocatalysis using semiconductors such as titanium dioxide $\left(\mathrm{TiO}_{2}\right)[9,10,11]$ and zinc oxide $(\mathrm{ZnO})[12,13,14]$. This method has several advantages, including efficient mineralization of various organic pollutants such as phenol and its potential to use visible and UV rays from sunlight $[15,16]$.

As a semiconductor with the band gap of $3.37 \mathrm{eV}$ [17], $\mathrm{ZnO}$ shall have enough energy for phenol degradation. However, the electrons and holes produced through photon irradiation often undergo rapid recombinations, thus decreasing the photocatalytic activity of $\mathrm{ZnO}$ [18]. One way to reduce the rate of recombination and improve charge separation is through doping, which creates a new donor or acceptor energy level between the semiconductor bandgap [19]. The addition of rare earth 
elements to ZnO for photocatalytic degradation of organic wastes has caused lower recombination rates on $\mathrm{ZnO}$ as a result of electron trapping in the acceptor energy levels created through the doping process [20, 21].

It has been reported that trivalent lanthanide $\left(\mathrm{Ln}^{3+}\right)$ dopants in $\mathrm{ZnO}$ assisted the creation of superoxide anions and were responsible for the creation of hydroxyl radicals [22]. These two species have been proposed as the primary causes of organic matter mineralization. Special attention has been put into the use of lanthanum ( $\mathrm{La}$ ) as a rare earth element and trivalent lanthanide, which addition gave a red-shift on the $\mathrm{ZnO}$ absorption spectrum, leading to the better activity of $\mathrm{ZnO}$ for Rhodamine B degradation [22]. The $\mathrm{La}^{3+}$ has shown the ability to occupy the ZnO crystal lattice as dopant through pyrolysis [22] and electrospinning-calcination method [23]. However, as both methods use high-temperature calcination, the nucleation and crystal growth of $\mathrm{ZnO}$ is rapid, resulting in a disruption of $\mathrm{ZnO}$ crystal lattice [22]. In addition, the methods often require either expensive equipment or high growth temperatures to achieve quality and crystallinity [24]. Another option of the synthesis method is low-temperature synthesis via a hydrothermal method, which has gained attention for its simplicity, reproducibility, and cost-effectiveness [25]. In this study, the effect of La species addition on $\mathrm{ZnO}$ synthesized using hydrothermal method towards its photocatalytic activity under visible and UV light irradiation was studied.

\section{Methodology}

\subsection{Equipment/Material}

The chemicals were obtained from Merck. For undoped and doped $\mathrm{ZnO}$ synthesis, zinc acetate dihydrate $\left(\mathrm{Zn}\left(\mathrm{CO}_{2} \mathrm{CH}_{3}\right)_{2} \cdot 2 \mathrm{H}_{2} \mathrm{O}\right.$, 99.5-101\%), sodium hydroxide $(\mathrm{NaOH}, 99 \%)$, lanthanum nitrate hexahydrate $\left(\mathrm{La}\left(\mathrm{NO}_{3}\right)_{3} \cdot 6 \mathrm{H}_{2} \mathrm{O}\right.$, analysis grade), and distilled water were used as received. For the photocatalytic activity test, phenol $\left(\mathrm{C}_{6} \mathrm{H}_{5} \mathrm{OH}, 99-100.5 \%\right)$ was used as the organic pollutant model. Two types of light sources were employed, which were halogen lamp (Dolan-Jenner MI157 150W) and UV lamp (UVP UVLS-28 EL 8W). For the characterizations of the $\mathrm{ZnO}$ and doped $\mathrm{ZnO}$ photocatalysts, diffuse reflectance ultraviolet-visible (DR UV-vis) spectrophotometer (JASCO V-760), spectrofluorometer (JASCO FP-8500), Fourier-transform infrared spectroscopy (FT-IR; JASCO FT/IR-6800), and powder X-ray diffractometer (XRD; Rigaku, SmartLab) were employed to study the optical, fluorescence properties, and functional groups in the materials, respectively. To determine the phenol percentage degradation, high-performance liquid chromatography (HPLC; Shimadzu, LC-20AT) with C-18 column (YMCTriart, S-5 $\mathrm{m}, 12 \mathrm{~nm}$ ) was used with acetonitrile (LC gradient grade) as the solvent.

\subsection{Experiment}

\subsubsection{Synthesis of Photocatalysts}

The syntheses of undoped and La-doped ZnO photocatalysts were done based on the method reported previously [26]. The $\mathrm{Zn}\left(\mathrm{CO}_{2} \mathrm{CH}_{3}\right)_{2} \cdot 2 \mathrm{H}_{2} \mathrm{O}$ and $\mathrm{NaOH}$ were each dissolved in $75 \mathrm{~mL}$ of water at a concentration of 0.1 and $0.2 \mathrm{M}$, respectively. The $\mathrm{Zn}\left(\mathrm{CO}_{2} \mathrm{CH}_{3}\right)_{2} \cdot 2 \mathrm{H}_{2} \mathrm{O}$ solution was then added dropwise to the $\mathrm{NaOH}$ solution, and the solution was stirred vigorously at $700 \mathrm{rpm}$ for an hour. The mixture was subsequently poured into a Teflon lined autoclave and heated using an oven at $150^{\circ} \mathrm{C}$ for 6 hours. The obtained $\mathrm{ZnO}$ suspension was separated through decantation. The ZnO slurry was then washed repeatedly using distilled water until the suspension $\mathrm{pH}$ reached 7 to get rid of any leftover precursor and byproducts before the drying process using the oven at $60^{\circ} \mathrm{C}$ for overnight.

Synthesis of La-doped ZnO photocatalysts was carried out similarly to the synthesis of $\mathrm{ZnO}$, except that the synthesis involved the addition of the $\mathrm{La}\left(\mathrm{NO}_{3}\right)_{3} \cdot 6 \mathrm{H}_{2} \mathrm{O}$ as the La source. The La source was added into the $\mathrm{Zn}\left(\mathrm{CO}_{2} \mathrm{CH}_{3}\right) 2.2 \mathrm{H}_{2} \mathrm{O}$ solution to give the $\mathrm{La} / \mathrm{Zn}$ composition of $0.01,0.1,1$, and $2 \mathrm{wt} \%$. The solution was then added into the $\mathrm{NaOH}$ solution while stirring the solution vigorously at $700 \mathrm{rpm}$. Similar steps to those mentioned for the synthesis of $\mathrm{ZnO}$ were then used to obtain the La-doped photocatalysts.

\subsubsection{Characterizations}

The undoped $\mathrm{ZnO}$ and $\mathrm{La}(1 \%) / \mathrm{ZnO}$ samples were characterized using XRD at room temperature. Crystallite size (D) was determined by a Scherrer equation, using the highest diffraction peak of the ( $\left.\begin{array}{lll}1 & 0 & 1\end{array}\right)$ plane. The lattice parameter was determined by employing the BravaisMiller system and the $d$ spacing calculated by Bragg's law. The functional group analysis of all undoped $\mathrm{ZnO}$ and Ladoped ZnO samples were investigated using FT-IR by preparing a potassium bromide $(\mathrm{KBr})$ pellet. In order to study the optical and fluorescence properties, the materials were also characterized by the DR UV-vis spectrophotometer, and spectrofluorometer, respectively. All the spectra were recorded at room temperature.

\subsubsection{Photocatalytic Tests}

To evaluate the photocatalytic activity of $\mathrm{ZnO}$ and La-doped $\mathrm{ZnO}$, the photocatalysts were tested for phenol degradation. The photocatalyst (50 mg) was suspended into $25 \mathrm{~mL}$ of $50 \mathrm{ppm}$ phenols. The suspension was then stirred for 2 hours under the dark condition to achieve the adsorption-desorption equilibrium, and followed by irradiation using a $150 \mathrm{~W}$ halogen lamp $(I=326$ $\left.\mu \mathrm{mol} / \mathrm{m}^{2} \mathrm{~s}\right)$ for 3 hours or using an $8 \mathrm{~W}$ UV lamp ( $I=2$ $\mu \mathrm{mol} / \mathrm{m}^{2} \mathrm{~s}$ ) for $6,12,15$, and 24 hours at the distance of 12 $\mathrm{cm}$ from the photocatalytic reactor. The suspension was then filtered using a filter membrane prior to the measurement of phenol content using HPLC. 


\section{Results and Discussion}

\subsection{Structural Analysis}

In order to determine the structure of $\mathrm{ZnO}$, the diffraction pattern of the synthesized $\mathrm{ZnO}$ was measured. As shown in Figure 1 (a), the synthesized $\mathrm{ZnO}$ gave diffraction peaks at $2 \theta$ of $31.65^{\circ}, 34.30^{\circ}, 36.13^{\circ}, 47.42^{\circ}$, $56.47^{\circ}, 62.73^{\circ}, 66.23^{\circ}, 67.81^{\circ}$, and $68.95^{\circ}$ associated with the diffractions of ( $\left.\begin{array}{lll}1 & 0 & 0\end{array}\right),\left(\begin{array}{lll}0 & 0 & 2\end{array}\right),\left(\begin{array}{lll}1 & 0 & 1\end{array}\right),\left(\begin{array}{lll}1 & 0 & 2\end{array}\right),\left(\begin{array}{lll}1 & 1 & 0\end{array}\right),(1$ 0 3), ( $\left(\begin{array}{lll}2 & 0 & 0\end{array}\right),\left(\begin{array}{lll}1 & 1 & 2\end{array}\right)$, and ( $\left(\begin{array}{lll}2 & 0 & 1\end{array}\right)$ planes, respectively. Based on the diffraction pattern, the crystalline $\mathrm{ZnO}$ was successfully synthesized, and the structure was in the wurtzite form.

As the representative sample, the diffraction pattern of $\mathrm{La}(1 \%) / \mathrm{ZnO}$ was measured and also shown in Figure 1 (a). After the addition of $1 \mathrm{wt} \%$ of La, no additional peaks were detected, indicating that no new structure such as lanthanum oxide was formed. Moreover, the doped $\mathrm{ZnO}$ still showed high crystallinity, and this result again confirmed that lanthanum doping did not disrupt the crystal lattices of $\mathrm{ZnO}$.
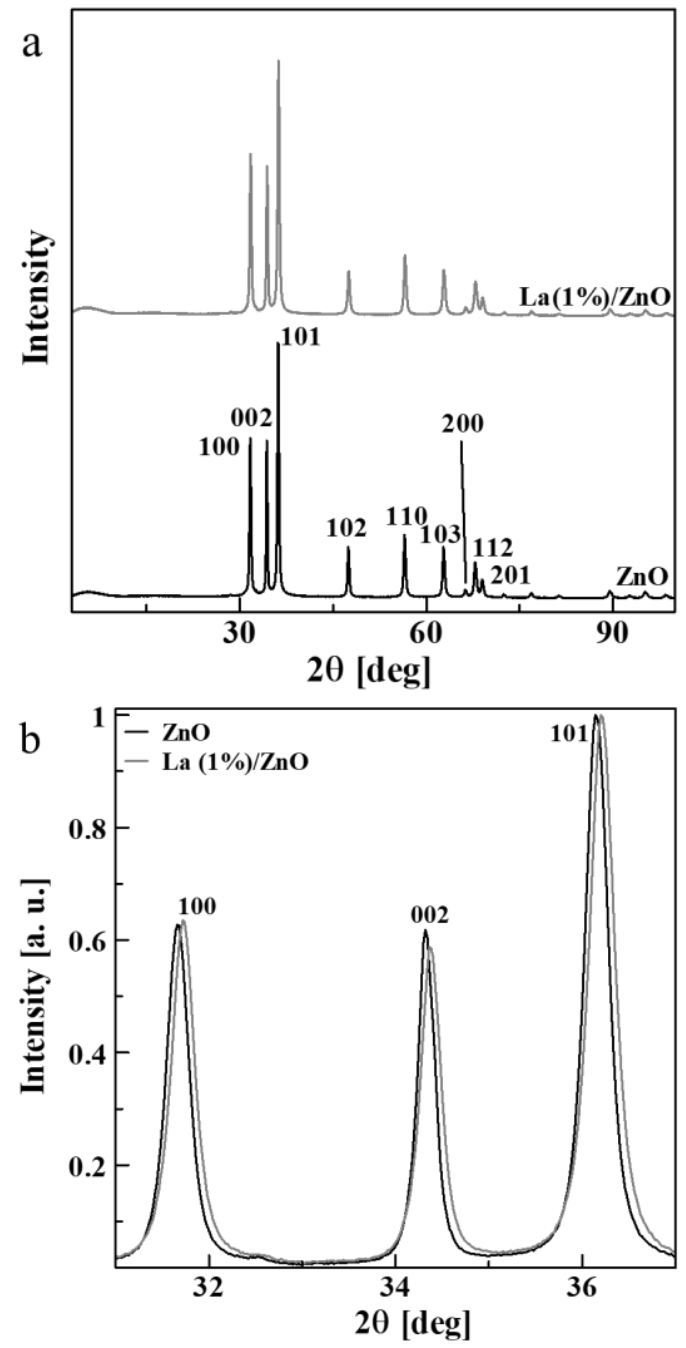

Figure 1. (a) XRD patterns of undoped and $\mathrm{La}(1 \%) / \mathrm{ZnO}$ and (b) their respective magnification at selected diffraction planes
The successful doping of La into $\mathrm{ZnO}$ crystal lattice was further confirmed from the shifting of diffractogram angles of doped $\mathrm{ZnO}$, as shown in Figure 1 (b). After the La addition, the diffraction angles were shifted to a larger angle due to the replacement of $\mathrm{Zn}^{2+}$ atom by $\mathrm{La}^{3+}$ atom in the $\mathrm{ZnO}$ crystal lattice. Since the atomic radius size of $\mathrm{La}^{3+}$ $(1.16 \AA)$ is larger than the atomic radius of $\mathrm{Zn}^{2+}(0.74 \AA)$ [23], the diffraction angle of $\mathrm{La}(1 \%)$-doped $\mathrm{ZnO}$ was slightly shifted to larger diffraction angle. Also, the bond distances in the crystal lattice became slightly shorter, which could be seen through the slight decrease in the lattice parameters shown in Table 1 . The reasonable decrease in the lattice constants was in good agreement with the previous result [22], which reported that the decrease was due to the mismatch atomic radius size of the $\mathrm{La}^{3+}$ and $\mathrm{Zn}^{2+}$, as well as the reduced oxygen vacancy. On the other hand, the values of $\alpha, \beta, \gamma$ were remained to be the same before and after La addition, suggesting that the La-doping did not affect the wurtzite structure of ZnO.

Table 1. Lattice parameters of undoped $\mathrm{ZnO}$ and La-doped ZnO samples

\begin{tabular}{ccc}
\hline Parameters & Pure ZnO & $\mathrm{La}(1 \%) / \mathrm{ZnO}$ \\
\hline $\mathrm{D}(\mathrm{nm})$ & 32.8 & 29.2 \\
$\mathrm{a}(\AA)$ & 3.255 & 3.254 \\
$\mathrm{~b}(\AA)$ & 3.255 & 3.254 \\
$\mathrm{c}(\AA)$ & 5.216 & 5.213 \\
$\alpha(\mathrm{deg})$ & 90 & 90 \\
$\beta(\mathrm{deg})$ & 90 & 90 \\
$\gamma(\mathrm{deg})$ & 120 & 120 \\
\hline
\end{tabular}

The effect of La addition on the crystallite size of the $\mathrm{ZnO}$ was investigated by using the Scherrer equation using the main peak at ( $\left.\begin{array}{lll}1 & 0 & 1\end{array}\right)$ plane. The addition of La to the $\mathrm{ZnO}$ also decreased the crystallite size of the synthesized ZnO from 32.8 to $29.2 \mathrm{~nm}$ after $1 \mathrm{wt} \%$ addition of La. It was reported that during the $\mathrm{ZnO}$ synthesis, La could form La-O-Zn entities on the surface of $\mathrm{ZnO}$, which slowed down the growth of $\mathrm{ZnO}$ [27]. The addition of La also distorted the lattice crystal of $\mathrm{ZnO}$, which could inhibit the $\mathrm{ZnO}$ growth [23].

\subsection{Functional Group Analysis}

To determine the functional groups in the synthesized $\mathrm{ZnO}$ and La-doped $\mathrm{ZnO}$ samples, the samples were measured using an FT-IR spectrophotometer. Figure 2 shows the FT-IR spectra of synthesized materials. The undoped $\mathrm{ZnO}$ showed the absorption at 3400 and $1639 \mathrm{~cm}^{-1}$ that corresponded to the stretching and bending vibrations of $\mathrm{O}-\mathrm{H}$ and $\mathrm{H}-\mathrm{O}-\mathrm{H}$ of water [28]. COO- and C-C vibrational peaks from acetic acid at 1415 and $896 \mathrm{~cm}^{-1}$ could also be observed [29]. Acetic acid, as a byproduct in the $\mathrm{ZnO}$ synthesis, may have been adsorbed at the surface of $\mathrm{ZnO}$ due to acid-base interactions between the acetic acid and the $\mathrm{ZnO}$. On the other hand, 
the stretching vibration of $\mathrm{Zn}-\mathrm{O}$ could be detected at 423 $\mathrm{cm}^{-1}[30,31]$.

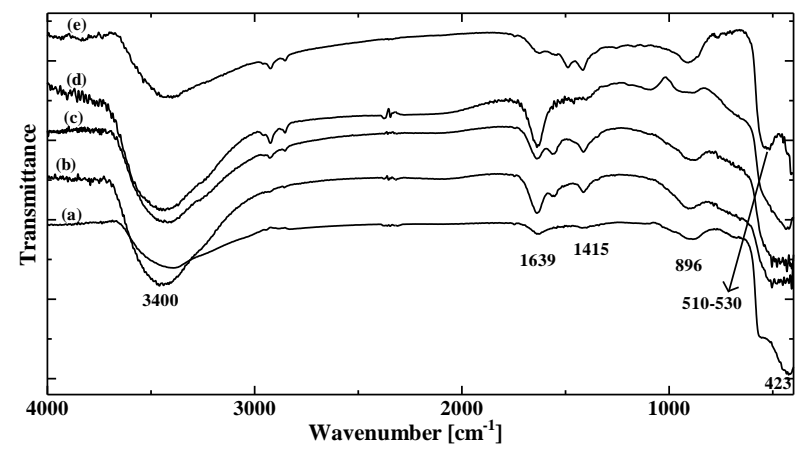

Figure 2. FT-IR spectra of (a) $\mathrm{ZnO}$, (b) $\mathrm{La}(0.01 \%) / \mathrm{ZnO}$, (c) $\mathrm{La}(0.1 \%) / \mathrm{ZnO}$, (d) $\mathrm{La}(1 \%) / \mathrm{ZnO}$, and (e) $\mathrm{La}(2 \%) / \mathrm{ZnO}$ samples respectively

After the La addition, similar peaks to those of the undoped $\mathrm{ZnO}$ could be observed, again confirming that the functional groups in the $\mathrm{ZnO}$ were not much affected with the La addition. The vibrational peaks from the acetic acid were found to be increased in intensity after La addition since the basicity of the lanthanum oxides could increase the basicity of $\mathrm{ZnO}$ and thus, increased the interaction with acetic acid. This acid-base interaction might prevent acetic acid desorption from the material surfaces despite repeated washing with distilled water after the materials were synthesized. After the addition of $2 \mathrm{wt} \%$ lanthanum, the La-O vibrational peak could be detected at $510-530 \mathrm{~cm}^{-1}$ [32]. This could be attributed to the formation of lanthanum oxide on the surface of $\mathrm{ZnO}$, which happened at excessive lanthanum doping concentrations [23].

\subsection{Optical Properties}

To determine the optical characteristic changes of ZnO after the addition of lanthanum, synthesized materials were measured using the DR UV-vis spectrophotometer and spectrofluorometer. The DR UVvis spectra of the materials were measured and shown in Figure 3 (a) as a plot of Kubelka-Munk (KM) function vs. wavelength. The $\mathrm{ZnO}$ and La-doped $\mathrm{ZnO}$ samples were shown to have strong absorption in the UV region with a maximum peak at $313 \mathrm{~nm}$. The addition of La did not affect the absorption of the maximum peak. However, it gave a blue shift on the ZnO band edge. The blue shift suggested the effect of particle size reduction in the La-doped $\mathrm{ZnO}$ samples, creating a quantum confinement effect on the doped material [26]. This result was in good agreement with the crystallite size determination, where $\mathrm{La}(1 \%)-$ ZnO sample showed a smaller crystallite size than the undoped $\mathrm{ZnO}$.

In order to determine the band gap energy of the undoped $\mathrm{ZnO}$ and La-doped $\mathrm{ZnO}$ samples, the Tauc plot was used, as shown in Figure 3 (b). La doping resulted in an increase of band gap energy from $3.22 \mathrm{eV}$ in undoped $\mathrm{ZnO}$ to $3.29,3.29,3.26$, and $3.26 \mathrm{eV}$ after the addition of $0.01,0.1,1$, and $2 \mathrm{wt} \%$ of La respectively. The increase of the band gap again showed the effect of particle size reduction of doped $\mathrm{ZnO}$, as discussed above.
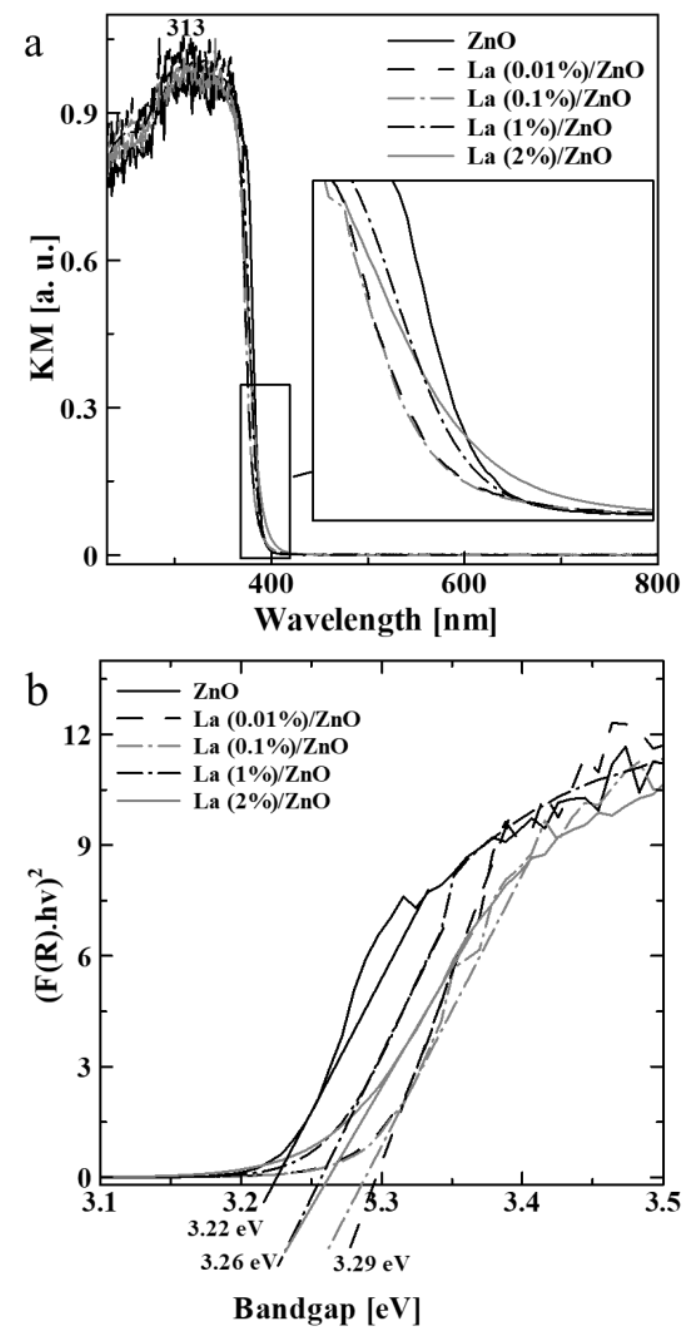

Figure 3. (a) DR UV-vis spectra and (b) Tauc plot of undoped and La-doped ZnO samples

Fluorescence spectra of the undoped and La-doped $\mathrm{ZnO}$ are shown in Figure 4. The excitation spectra were measured at an emission wavelength of $558 \mathrm{~nm}$, while the emission spectra were measured at excitation wavelengths of $372-384 \mathrm{~nm}$ based on each respective excitation peak, which changed after the addition of La. The maximum excitation wavelength in Figure 4 (a) showed a red shift from 372 to 378,380 , and $384 \mathrm{~nm}$ after $0.01,0.1$, and $1 \mathrm{wt} \%$ lanthanum addition, which suggested the exchange interaction of $\mathrm{sp}-\mathrm{d}$ orbitals in $\mathrm{ZnO}$ band electrons and localized d electrons of La doping in the semiconductor matrix [33]. This result showed the successful creation of the acceptor level by La in the $\mathrm{ZnO}$ band gap. However, after $2 \mathrm{wt} \%$ addition of La, the excitation peak was blue-shifted to $356 \mathrm{~nm}$. This could be due to the influence of surface lanthanum oxide at excessive addition of La [23], in which its excitation wavelength was at $300 \mathrm{~nm} \mathrm{[34].}$

The yellow emission of $\mathrm{ZnO}$ at $558 \mathrm{~nm}$ is attributed to the electron transition from the conduction band (CB) of ZnO to the oxygen vacancy $\left(\mathrm{V}_{\mathrm{o}}\right)$ [35], indicating the 
presence of oxygen vacancy defect in the synthesized ZnO. By the addition of 0.01 and $0.1 \mathrm{wt} \%$ of La, the emission intensity was reduced, which indicated the lower $\mathrm{V}_{\mathrm{o}}$ concentration on $\mathrm{ZnO}$ after the La addition. The suppression of oxygen vacancies was due to the bond strength differences in $\mathrm{Zn}-\mathrm{O}$ and $\mathrm{La}-\mathrm{O}$ bonds. Doping of $\mathrm{La}^{3+}$ ions into $\mathrm{ZnO}$ would create the La-O bonds, which have a higher diatomic bond dissociation energy than Zn$\mathrm{O}$ bonds. The reported values for $\mathrm{Zn}-\mathrm{O}$ bonds and La-O bonds were $\leq 250$ and $798 \mathrm{~kJ} \mathrm{~mol}^{-1}$ [36], respectively. This difference indicated that the La-O bonds enhanced the average bond strength between oxygen and neighboring cations and decreased the possibility of oxygen-cation dissociation during synthesis, thus decreased the $\mathrm{V}_{\mathrm{o}}$ concentration [37]. However, when the addition of La was $1 \mathrm{wt} \%$, the emission intensity was not much affected as it gave a similar intensity to the $\mathrm{ZnO}$, implying an abrupt increase of $V_{0}$ concentration. This result was in good agreement with the work reported by Park et al. [37]. In contrast, at $2 \mathrm{wt} \%$ La addition, the emission intensity was at its lowest one due to the formation of lanthanum oxide at the ZnO surface [23], which could hinder the photon absorption of material, thus decreased the emission intensity as well.
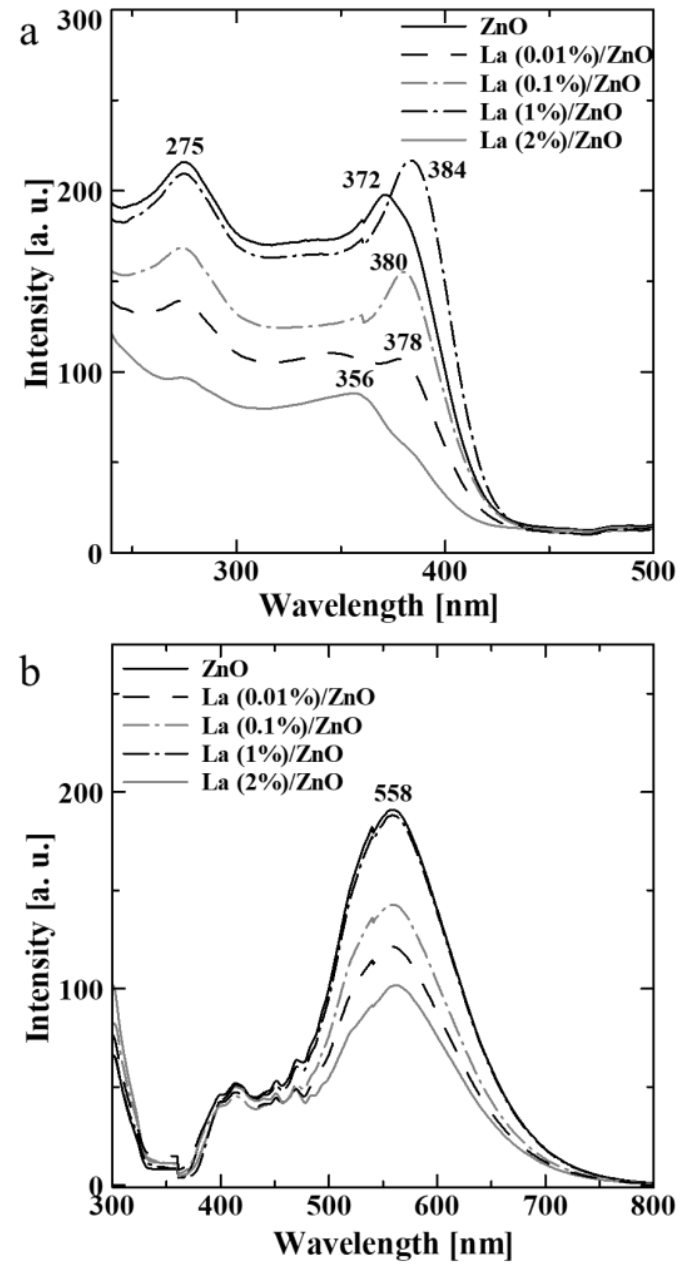

Figure 4. (a) Excitation and (b) emission spectra of undoped $\mathrm{ZnO}$ and La-doped $\mathrm{ZnO}$ samples monitored at an emission wavelength of $558 \mathrm{~nm}$ and excitation wavelengths of $356-384 \mathrm{~nm}$

\subsection{Photocatalytic Activities}

Undoped $\mathrm{ZnO}$ and La-doped $\mathrm{ZnO}$ samples were tested for their photocatalytic phenol degradation under visible and UV light. The photocatalytic activity of synthesized materials under visible light for 3 hours is depicted in Figure 5. After La addition, photocatalytic activity enhancement of $\mathrm{ZnO}$ could be achieved, from $0.1 \%$ phenol degradation using undoped $\mathrm{ZnO}$ to $1.4,2.8,6.1$, and $5.6 \%$ phenol degradation using $\mathrm{La}(0.01 \%) / \mathrm{ZnO}, \mathrm{La}(0.1 \%) / \mathrm{ZnO}$, $\mathrm{La}(1 \%) / \mathrm{ZnO}$, and $\mathrm{La}(2 \%) / \mathrm{ZnO}$, respectively. The improved photocatalytic activity could be due to several reasons. The smaller crystallite size of the La-doped $\mathrm{ZnO}$ samples could be a sign of smaller particle size, which could give a larger specific surface area of the La-doped $\mathrm{ZnO}$ [38]. Another reason was the creation of acceptor energy level by La in the ZnO bandgap, which could inhibit electron-hole recombination in the $\mathrm{ZnO}$ [23].

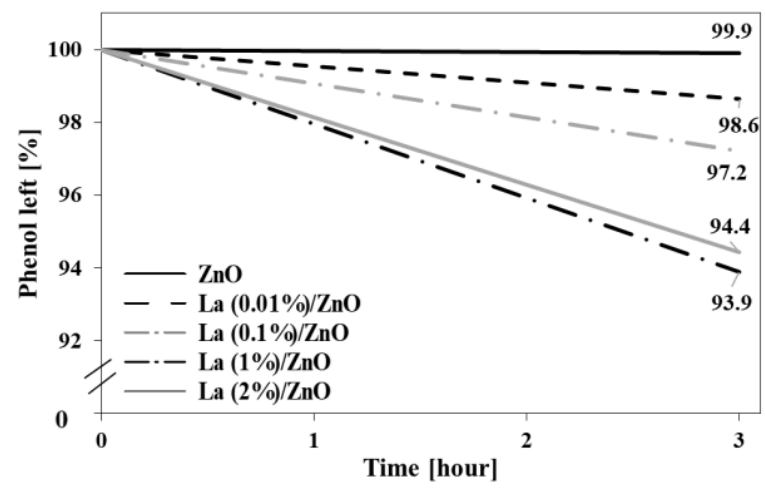

Figure 5. Photocatalytic phenol degradation on undoped $\mathrm{ZnO}$ and La-doped $\mathrm{ZnO}$ samples under visible light

The photocatalytic activity of doped $\mathrm{ZnO}$ and Laundoped $\mathrm{ZnO}$ photocatalysts under UV light for 6, 12, 15, and 24 hours is depicted in Figure 6. After the addition of 0.01 and $0.1 \mathrm{wt} \% \mathrm{La}$, the photocatalytic activity of $\mathrm{ZnO}$ declined from $93.6 \%$ to 13.1 and $14.1 \%$ phenol degradation, respectively, after 24 hours-reaction. This is caused by the decrease of $\mathrm{V}_{0}$ concentration after La doping. As a donor, the existence of $\mathrm{V}_{\mathrm{o}}$ can improve electron excitation and the production of hydroxyl radical, which was the primary species responsible for phenol photomineralization [39]. After $1 \mathrm{wt} \%$ addition of $\mathrm{La}$, the photocatalytic activity of ZnO gave an increase to $100 \%$ phenol degradation after 24 hours-reaction. Referring to its $\mathrm{V}_{\mathrm{o}}$ concentration in Figure 4, it was clear that the photocatalytic activity of ZnO under UV light has a strong relation with $\mathrm{V}_{\mathrm{o}}$ concentrations. The $\mathrm{V}_{\mathrm{o}}$ as donors could act as a recombination center, which improved electron and hole separation [35], resulting in higher hydroxyl radical production and, thus, higher phenol degradation. After $2 \mathrm{wt} \%$ addition of $\mathrm{La}$, the photocatalytic activity of $\mathrm{ZnO}$ decreased again to $35.2 \%$ due to the formation of lanthanum oxide at the $\mathrm{ZnO}$ surface [23], which could hinder ZnO photon absorption and limit contact between phenol and $\mathrm{ZnO}$. 
Based on the photocatalytic activity tests under visible and UV light, the optimum lanthanum doping concentration on $\mathrm{ZnO}$ was $1 \mathrm{wt} \%$. At $1 \mathrm{wt} \%$ addition, $\mathrm{V}_{\mathrm{o}}$ concentration increased along with a red shift of maximum excitation wavelength due to acceptor energy level introduction by lanthanum [33]. The low doping concentrations $(0.01,0.1 \mathrm{wt} \%)$ decreased the $\mathrm{V}_{\mathrm{o}}$ concentration on $\mathrm{ZnO}$ that resulted in low photocatalytic activity. On the other hand, the excess La doping ( $2 \mathrm{wt} \%$ ) limited photon absorption and phenol-ZnO surface contact due to the formation of surface lanthanum oxide [23].

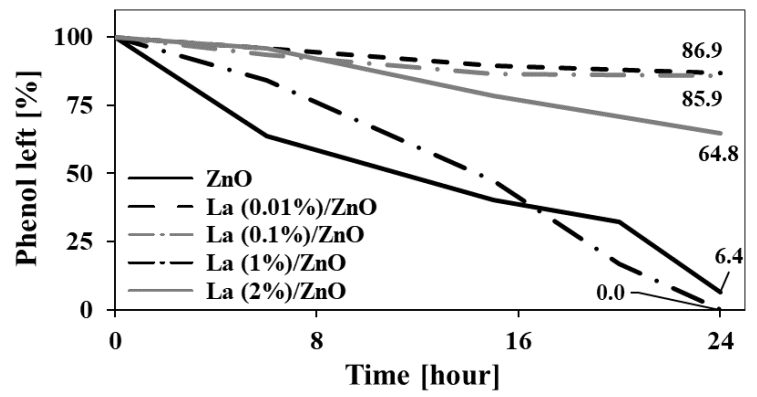

Figure 6. Photocatalytic phenol degradation on undoped ZnO and La-doped ZnO samples under UV light

\section{Conclusion}

Undoped ZnO and La-doped ZnO samples having $\mathrm{La} / \mathrm{Zn}$ composition of $0.01,0.1,1$, and $2 \mathrm{wt} \%$ were successfully synthesized by the hydrothermal method. XRD patterns showed that ZnO has a crystalline wurtzite structure, and the structure was not disturbed by the addition of La. However, the diffraction of the $\mathrm{ZnO}$ was shifted to a larger angle, indicating the successful substitution of $\mathrm{Zn}$ by the La dopant. The crystallite size was also found to be decreased with the addition of La. FTIR spectra detected La-O stretching vibration due to the formation of surface lanthanum oxide at $2 \mathrm{wt} \% \mathrm{La}$ addition. The fluorescence spectra of La-doped $\mathrm{ZnO}$ showed the successful introduction of acceptor energy level by lanthanum doping. $\mathrm{La}(1 \%) / \mathrm{ZnO}$ exhibited a higher emission intensity as compared to other doped samples. Photocatalytic tests showed that the best sample having the highest photocatalytic activity for phenol degradation under both visible and UV light was $\mathrm{La}(1 \%) / \mathrm{ZnO}$. Under visible light for 3 hours, the activity of undoped $\mathrm{ZnO}$ increased more than sixty times from $0.1 \%$ to $6.1 \%$. On the other hand, under UV light for 24 hours, the activity increased from $93.6 \%$ to $100 \%$. These improvements of photocatalytic activity were contributed from several parameters, including the reduced crystallite size, introduction of acceptor energy level by lanthanum, and high $\mathrm{V}_{\mathrm{o}}$ concentration.

\section{Acknowledgment}

Support from Directorate General of Strengthening Research and Development, Ministry of Research, Technology, and Higher Education of the Republic of Indonesia via the World Class Research scheme (WCR
2019, No. 041/SP2H/LT/MULTI/L7/2019 and No. 014/MACHUNG/LPPM/SP2H-LIT-MULTI/III/2019) is greatly acknowledged.

\section{References}

[1] N. Calace, E. Nardi, B. M. Petronio and M. Pietroletti, Adsorption of phenols by papermill sludges, Environmental Pollution, 118, 3, (2002), 315-319 https://doi.org/10.1016/S0269-7491(01)00303-7

[2] Toraj Mohammadi and Pezhman Kazemi, Taguchi optimization approach for phenolic wastewater treatment by vacuum membrane distillation, Desalination and Water Treatment, 52, 7-9, (2014), 1341-1349 https://doi.org/10.1080/19443994.2013.794557

[3] Wen Ping Cheng, Wei Gao, Xinyu Cui, Jing Hong Ma and Rui Feng Li, Phenol adsorption equilibrium and kinetics on zeolite X/activated carbon composite, Journal of the Taiwan Institute of Chemical Engineers, 62, (2016), 192-198

https://doi.org/10.1016/j.jtice.2016.02.004

[4] Giada La Scalia, Rosa Micale, Luigi Cannizzaro and Francesco Paolo Marra, A sustainable phenolic compound extraction system from olive oil mill wastewater, Journal of Cleaner Production, 142, (2017), 3782-3788 https://doi.org/10.1016/j.jclepro.2016.10.086

[5] Arjunan Babuponnusami and Karuppan Muthukumar, A review on Fenton and improvements to the Fenton process for wastewater treatment, Journal of Environmental Chemical Engineering, 2, 1, (2014), 557-572 https://doi.org/10.1016/j.jece.2013.10.011

[6] Yousef Dadban Shahamat, Mahdi Farzadkia, Simin Nasseri, Amir Hossein Mahvi, Mitra Gholami and Ali Esrafili, Magnetic heterogeneous catalytic ozonation: a new removal method for phenol in industrial wastewater, Journal of Environmental Health Science and Engineering, 12, 50, (2014), 50 https://doi.org/10.1186/2052-336X-12-50

[7] Yuxian Wang, Li Zhou, Xiaoguang Duan, Hongqi Sun, Ee Lee Tin, Wanqin Jin and Shaobin Wang, Photochemical degradation of phenol solutions on $\mathrm{Co}_{3} \mathrm{O}_{4}$ nanorods with sulfate radicals, Catalysis Today, 258, (2015), 576-584 https://doi.org/10.1016/j.cattod.2014.12.020

[8] Laura G. Cordova Villegas, Neda Mashhadi, Miao Chen, Debjani Mukherjee, Keith E. Taylor and Nihar Biswas, A Short Review of Techniques for Phenol Removal from Wastewater, Current Pollution Reports, 2, 3, (2016), 157-167

https://doi.org/10.1007/s40726-016-0035-3

[9] M. A. Barakat, R. I. Al-Hutailah, E. Qayyum, J. Rashid and J. N. Kuhn, Pt nanoparticles/ $/ \mathrm{TiO}_{2}$ for photocatalytic degradation of phenols in wastewater, Environmental Technology, 35, 2, (2014), 137-144 https://doi.org/10.1080/09593330.2013.820796

[10] Marissa Choquette-Labbé, A. Wudneh Shewa, A. Jerald Lalman and R. Saravanan Shanmugam, Photocatalytic Degradation of Phenol and Phenol Derivatives Using a Nano-TiO2 Catalyst: Integrating 
Quantitative and Qualitative Factors Using Response Surface Methodology, Water, 6, 6, (2014), 1785-1806 https://doi.org/10.3390/w6061785

[11] Asma Turki, Chantal Guillard, Frédéric Dappozze, Zouhaier Ksibi, Gilles Berhault and Hafedh Kochkar, Phenol photocatalytic degradation over anisotropic $\mathrm{TiO}_{2}$ nanomaterials: Kinetic study, adsorption isotherms and formal mechanisms, Applied Catalysis B: Environmental, 163, (2015), 404-414 https://doi.org/10.1016/j.apcatb.2014.08.010

[12] Saravanan Rajendran, Mohammad Mansoob Khan, F. Gracia, Jiaqian Qin, Vinod Kumar Gupta and Stephen Arumainathan, $\mathrm{Ce}^{3+}$-ion-induced visible-light photocatalytic degradation and electrochemical activity of $\mathrm{ZnO} / \mathrm{CeO}_{2}$ nanocomposite, Scientific Reports, 6, 1, (2016), 31641 https://doi.org/10.1038/srep31641

[13] Jingjing Jiang, Hongtao Wang, Xiaodong Chen, Shuo Li, Tengfeng Xie, Dejun Wang and Yanhong Lin, Enhanced photocatalytic degradation of phenol and photogenerated charges transfer property over BiOIloaded ZnO composites, Journal of Colloid and Interface Science, 494, (2017), 130-138 https://doi.org/10.1016/j.jcis.2017.01.064

[14] V. Vaiano, M. Matarangolo, J. J. Murcia, H. Rojas, J. A. Navío and M. C. Hidalgo, Enhanced photocatalytic removal of phenol from aqueous solutions using $\mathrm{ZnO}$ modified with Ag, Applied Catalysis B: Environmental, 225, (2018), 197-206 https://doi.org/10.1016/j.apcatb.2017.11.075

[15] NikAthirah Yusoff, Soon-An Ong, Li-Ngee Ho, YeeShian Wong and WanFadhilah Khalik, Degradation of phenol through solar-photocatalytic treatment by zinc oxide in aqueous solution, Desalination and Water Treatment, 54, 6, (2015), 1621-1628 https://doi.org/10.1080/19443994.2014.908414

[16]Mohamed Gar Alalm, Ahmed Tawfik and Shinichi Ookawara, Solar photocatalytic degradation of phenol by TiO2/AC prepared by temperature impregnation method, Desalination and Water Treatment, 57, 2, (2016), 835-844 https://doi.org/10.1080/19443994.2014.969319

[17] Zhong Lin Wang, Zinc oxide nanostructures: growth, properties and applications, Journal of Physics: Condensed Matter, 16, 25, (2004), R829-R858 https://doi.org/10.1088/0953-8984/16/25/R01

[18] Sangeeta Adhikari, Debasish Sarkar and Giridhar Madras, Highly efficient $\mathrm{WO}_{3}-\mathrm{ZnO}$ mixed oxides for photocatalysis, RSC Advances, 5, 16, (2015), 1189511904 http://dx.doi.org/10.1039/C4RA13210F

[19] Klaus Ellmer and André Bikowski, Intrinsic and extrinsic doping of $\mathrm{ZnO}$ and $\mathrm{ZnO}$ alloys, Journal of Physics D: Applied Physics, 49, 41, (2016), 413002 http://dx.doi.org/10.1088/0022-3727/49/41/413002

[20]Jin-Chung Sin, Sze-Mun Lam, Keat-Teong Lee and Abdul Rahman Mohamed, Preparation of rare earthdoped $\mathrm{ZnO}$ hierarchical micro/nanospheres and their enhanced photocatalytic activity under visible light irradiation, Ceramics International, 40, 4, (2014), 5431-5440 https://doi.org/10.1016/j.ceramint.2013.10.128
[21] Santanu Das, Sukhen Das, Anirban Roychowdhury, Dipankar Das and Soumyaditya Sutradhar, Effect of Gd doping concentration and sintering temperature on structural, optical, dielectric and magnetic properties of hydrothermally synthesized $\mathrm{ZnO}$ nanostructure, Journal of Alloys and Compounds, 708, (2017), 231-246 https://doi.org/10.1016/j.jallcom.2017.02.216

[22]M. Khatamian, A. A. Khandar, B. Divband, M. Haghighi and S. Ebrahimiasl, Heterogeneous photocatalytic degradation of 4-nitrophenol in aqueous suspension by $\mathrm{Ln}\left(\mathrm{La}^{3+}, \mathrm{Nd}^{3+}\right.$ or $\left.\mathrm{Sm}^{3+}\right)$ doped ZnO nanoparticles, Journal of Molecular Catalysis A: Chemical, 365, (2012), 120-127 https://doi.org/10.1016/j.molcata.2012.08.018

[23] Petronela Pascariu, Mihaela Homocianu, Corneliu Cojocaru, Petrisor Samoila, Anton Airinei and Mirela Suchea, Preparation of La doped $\mathrm{ZnO}$ ceramic nanostructures by electrospinning-calcination method: Effect of $\mathrm{La}^{3+}$ doping on optical and photocatalytic properties, Applied Surface Science, 476, (2019), 16-27

https://doi.org/10.1016/j.apsusc.2019.01.077

[24]Ke Sun, Wei Wei, Yong Ding, Yi Jing, Zhong Lin Wang and Deli Wang, Crystalline ZnO thin film by hydrothermal growth, Chemical Communications, 47, 27, (2011), 7776-7778 http://dx.doi.org/10.1039/C1CC11397F

[25]Sunandan Baruah and Joydeep Dutta, Hydrothermal growth of $\mathrm{ZnO}$ nanostructures, Science and Technology of Advanced Materials, 10, 1, (2009), 013001 http://dx.doi.org/10.1088/1468-6996/10/1/013001

[26]Aneesh Madathil, N. Pacheri, K. A. Vanaja and M. K. Jayaraj, Synthesis of ZnO nanoparticles by hydrothermal method, Proc. SPIE 6639, Nanophotonic Materials IV, 66390J (17 September 2007), San Diego, California, 2007 https://doi.org/10.1117/12.730364

[27]Tiekun Jia, Weimin Wang, Fei Long, Zhengyi Fu, Hao Wang and Qingjie Zhang, Fabrication, characterization and photocatalytic activity of Ladoped ZnO nanowires, Journal of Alloys and Compounds, 484, 1, (2009), 410-415 https://doi.org/10.1016/j.jallcom.2009.04.153

[28]Chengshuai Liu, Kaimin Shih, Yuanxue Gao, Fangbai Li and Lan Wei, Dechlorinating transformation of propachlor through nucleophilic substitution by dithionite on the surface of alumina, Journal of Soils and Sediments, 12, 5, (2012), 724-733 https://doi.org/10.1007/s11368-012-0506-0

[29]Jean-Joseph Max and Camille Chapados, Infrared Spectroscopy of Aqueous Carboxylic Acids: Comparison between Different Acids and Their Salts, The Journal of Physical Chemistry A, 108, 16, (2004), 3324-3337 https://doi.org/10.1021/jp036401t

[30]M Kooti and A Naghdi Sedeh, Microwave-assisted combustion synthesis of ZnO nanoparticles, Journal of Chemistry, 2013, Article ID 562028 (2012), 1-4 https://doi.org/10.1155/2013/562028 
[31] Bhanu P. Gangwar, Veerabhadraiah Palakollu, Archana Singh, Sriram Kanvah and Sudhanshu Sharma, Combustion synthesized $\mathrm{La}_{2} \mathrm{O}_{3}$ and $\mathrm{La}(\mathrm{OH})_{3}$ : recyclable catalytic activity towards Knoevenagel and Hantzsch reactions, RSC Advances, 4, 98, (2014), 55407-55416 http://dx.doi.org/10.1039/C4RA08353A

[32]Weiwei Lou, Yiwen Dong, Hualin Zhang, Yifan Jin, Xiaohui Hu, Jianfeng Ma, Jinsong Liu and Gang Wu, Preparation and Characterization of LanthanumIncorporated Hydroxyapatite Coatings on Titanium Substrates, International Journal of Molecular Sciences, 16, 9, (2015), 21070-21086

https://doi.org/10.3390/ijms160921070

[33] Yamina Ghozlane Habba, Martine CapochichiGnambodoe and Yamin Leprince-Wang, Enhanced Photocatalytic Activity of Iron-Doped $\mathrm{ZnO}$ Nanowires for Water Purification, Applied Sciences, 7, 11, (2017), 1185 https://doi.org/10.3390/app7111185

[34]Aman Pandey, Gunisha Jain, Divya Vyas, Silvia Irusta and Sudhanshu Sharma, Nonreducible, Basic $\mathrm{La}_{2} \mathrm{O}_{3}$ to Reducible, Acidic $\mathrm{La}_{2-\mathrm{x}} \mathrm{Sb}_{\mathrm{x}} \mathrm{O}_{3}$ with Significant Oxygen Storage Capacity, Lower Band Gap, and Effect on the Catalytic Activity, The Journal of Physical Chemistry C, 121, 1, (2017), 481-489 https://doi.org/10.1021/acs.jpcc.6b10821

[35]Fatma Kayaci, Sesha Vempati, Inci Donmez, Necmi Biyikli and Tamer Uyar, Role of zinc interstitials and oxygen vacancies of $\mathrm{ZnO}$ in photocatalysis: a bottomup approach to control defect density, Nanoscale, 6, 17, (2014), 10224-10234 http://dx.doi.org/10.1039/C4NR01887G

[36]Yu-Ran Luo, Comprehensive Handbook of Chemical Bond Energies, first ed., CRC Press, 2007

[37]Ji Hun Park, Yeong Ju Lee, Jong-Seong Bae, Bum-Su Kim, Yong Chan Cho, Chikako Moriyoshi, Yoshihiro Kuroiwa, Seunghun Lee and Se-Young Jeong, Analysis of oxygen vacancy in Co-doped $\mathrm{ZnO}$ using the electron density distribution obtained using MEM, Nanoscale Research Letters, 10, 1, (2015), 186 https://doi.org/10.1186/s11671-015-0887-2

[38]Isabelle Dubois, Stellan Holgersson, Stefan Allard and Maria Malmström, Correlation between particle size and surface area for chlorite and K-feldspar, in: Birkle, Torres-Alvarado (Eds.) Water-Rock Interaction - Proceedings of the 13th International Conference on Water-Rock Interaction, WRI-13, Taylor \& Francis Group, London, 2010,

[39]Juan Yang, Jun Dai, Chuncheng Chen and Jincai Zhao, Effects of hydroxyl radicals and oxygen species on the 4-chlorophenol degradation by photoelectrocatalytic reactions with $\mathrm{TiO}_{2}$-film electrodes, Journal of Photochemistry and Photobiology A: Chemistry, 208, 1, (2009), 66-77 https://doi.org/10.1016/j.jphotochem.2009.08.007 